\title{
Migration policies and international labour market competition
}

By

\author{
Mehdi Chowdhury
}

\begin{abstract}
Many developing countries compete with each other to send migrants to rich and developed countries. This article analyses migration policy of two sending and one receiving countries with such migration. The labour exporting countries set the number of migrants unilaterally and compete à la Cournot with each other. The receiving country imposes origin-based migration tax rates. To maximise the benefit of migration, the receiving country uses discriminatory tax rates where the tax burden is highest for the country with the highest labour endowment.
\end{abstract}

Key Words: Migration policy, competition, discrimination JEL Classifications: F22

Correspondence to: Mehdi Chowdhury, Business School, Bournemouth University 89 Holdenhurst Road, Bournemouth, BH8 8EB, UK.

E-mail: mchowdhury@bournemouth.ac.uk

Tel: +44 (0)1202961397

\section{Acknowledgement:}

The paper has been developed from a chapter of the $\mathrm{PhD}$ thesis of the author, completed at the School of Economics, University of Nottingham. The author is grateful to Indraneel Dasgupta, Arijit Mukherjee, Dijkastra Bouwe and Bibhas Saha for their valuable comments and suggestions. All remaining errors are the author's. 


\title{
Migration policies and international labour market competition
}

\begin{abstract}
Many developing countries compete with each other to send migrants to rich and developed countries. This article analyses migration policy of two sending and one receiving countries with such migration. The labour exporting countries set the number of migrants unilaterally and compete à la Cournot with each other. The receiving country imposes origin-based migration tax rates. To maximise the benefit of migration, the receiving country uses discriminatory tax rates where the tax burden is highest for the country with the highest labour endowment.
\end{abstract}

Key Words: Migration policy, competition, discrimination

JEL Classifications: F22

\section{Introduction}

This article aims to provide with an understanding of a receiving country's response to the competition of the sending countries in international labour market. It is now commonly believed that international migration via remittances, networks, human capital investments etc. substantially benefits the developing countries. The governments of many Asian and Latin American countries now have programmes to send migrants to the rich and developed countries. Through these programmes, the sending countries compete with each other in international labour market. References 
of such competition can be found in governments' reports or newspapers articles. The migration literature however is relatively limited in addressing this issue.

The discussions available in policy papers and newspaper articles about ongoing competition of countries are to some extent vague. For example, the report of the International Organization for Migration on labour market in Asia (IOM, 2003) makes several comments on competition (e.g. page $21,39,73$ ) without any detailed analysis. However, the report mentioned that the competition is severely undermining the bargaining power of the countries as they are seeking to balance 'promotion' of overseas employment and 'protection' of migrants. The presence of on-going competition among stakeholders can be also noticed by studying the bilateral migration agreements and/or labour recruitment procedures of contractual/temporary migrant workers. One example is Canada's Seasonal Agricultural Workers Program, which has two different bilateral agreements with Mexico and Caribbean countries for temporary migration of agricultural labour. In 2001, Canada for the first time decided to meet the two counterparts to negotiate wage related issues, but the agricultural employers in Canada objected, fearing an increase of bargaining power of workers (Verma 2003, page 60). We also observe competition of countries for labour migration in the Persian Gulf countries. The Gulf countries, i.e. Saudi Arabia, Kuwait, Oman, Bahrain, UAE and Qatar are the major importers of migrant labour in the Asian region. The Gulf news (http://gulfnews.com/) and other newspapers of Asia from time to time publish news concerning migration. An explicit note on competition is available in Migrants Right (Migrants Right, 2008) where it mentioned a case of a $50 \%$ decrease in the demand for Filipino housemaids following an increase in the reservation wage rate of housemaids by the Philipinnes' government. Another explicit reference to competition is available in Shah (2012) that mentioned that labour supply 
from various Asian and Non-Asian countries (e.g. Ethiopia) keeps the wage in the Gulf low. From the above it appears that the labour sending countries in the Gulf are setting their policies unilaterally. The receiving countries of the Gulf in this regard are more organised. They together have formed Gulf Cooperation Council (GCC) that addresses the demand as well as the management issues of the migrants. They follow a system called Kafala in which migrants need sponsorship from a permanent resident of the Gulf (Longva, 1999, Wickramasekara 2016 ). However, there exists no such coalition of the labour sending countries.

The observations mentioned above show the need to direct a study to evaluate the economic effects of competition in international labour market. Chowdhury (2014) developed a model of competition for international migration where labour markers are integrated. In an integrated labour market, people can move from one country to another country without explicit participations of the governments. However if labour markets are not integrated, as in most of the cases, labour often has to migrate via governments' channels.

Hence, this paper develops a model, similar to Chowdhury (2014) where two countries export labour to a third country to receive remittances. However, instead of direct migration by the individuals, the migrants' number is decided by the sending countries with a view to maximise the national incomes. In doing so, the two sending countries act as Cournot-type competitors. The receiving country uses tax policies to fulfil its national objectives and designs the policies foreseeing the labour export of the two countries. The tax rates are regarded as proxies of various monetary and nonmonetary barriers/costs involved in migration which are above the administrative costs in the receiving country. Though the literature is still limited, the analysis of optimal policies of the sending and receiving countries with government managed 
programmes received attention of a number of papers i.e. Schiff (2007), Djajić et al. (2012) and Djajić (2013) which analyse policy interactions between host and source countries with guest-workers programmes. Chowdhury (2014) analyses the optimal policies of the host and source countries when labour markets are integrated. Chowdhury and Mukherjee (2015) analyses how labour market integration affects the welfare of consumers through increased research and development. The main aim of the current paper, on the other hand, is to analyse the optimal policy of the host country when source countries compete with each other for the share of international labour market through government managed programmes.

We observe often, that the receiving country controls the number of migrants using quota or quantity restriction. The paper, instead, assumes that the sending countries can send as many as they want to the receiving country. This assumption limits the policy variables available to the sending countries, however, assists to isolate some interesting effects of competition in a simple and tractable way. One is the use of discriminatory tax policy by the receiving country on the basis of labour endowment where the country with the highest labour endowment pays the highest per capita tax. Comi and Grasseni (2012) found in 9 European countries that workers with the same characteristics as permanent workers would receive lower wages if they worked on temporary contracts. Our results suggest that the receiving country may also discriminate on the basis of the country of origin. The result is consistent with the notions of competition and market power mentioned in IOM (2003).

The idea of the competition comes from Chau and Kanbur (2006) that modelled the competition between two Southern countries in labour standards and showed that the Northern importing country can take the benefit away from the Southern countries by increasing tax rates. Instead of labour standard, we assume that 
the countries compete by sending labour. The model of this article is aligned with the modelling practices of strategic trade policy literature, especially of Brander and Spencer (1985). Some papers have incorporated import tax in the Brander-Spencer framework and this article bears some similarities with them.

International migration has many dimensions and it should be noted that it is impossible to capture all of that in a single paper. In the paper, we make no attempt to address issues like brain drain, migration networks, migration cost, illegal migration or the motives of remittances. Our analysis is therefore partial in essence and aiming for a tractable analysis capable of providing a simple and qualitative understanding of an issue, i.e. competition of countries in international labour market. A detailed survey of the recent international migration literature is available in Docquier and Rapoport (2012). We note also that the international migration literature is still highly biased in analysing only the developed receiving countries' benefit and cost. There is a great need for works that address issues at par with the need of the developing countries ${ }^{1}$. This need has been greatly ignored by the existing literature on the 'economics of immigration'.

The organisation of the remaining sections of the paper is as follows. The second section introduces the model, basic notations and clarifies the mechanism of labour migration. The third section deals with some comparative statics results. The forth section discusses the imposition of tax rates by the importing country. The fifth or the last section concludes the paper.

\footnotetext{
${ }^{1}$ A similar view with reference of the migration in the Gulf has been expressed by Oommen (2015).
} 


\section{The Model}

\subsection{Basic Assumptions and Notations}

The basis assumptions and notations of the model are similar to Chowdhury (2014). We assume that there are three open economies $C, I$ and $U$ that produce two internationally traded goods $X_{1}$ and $X_{2}$. The prices of the goods are fixed. The units are selected in a way that relative price of one unit of a good is equal to 1 . Endowments of labour are fixed, denoted by $\bar{L}_{i}$ for country $i \in\{C, I\}$ and $\bar{L}_{u}$ for country $U$. The technologies and labour endowments of the countries are such that country $C$ and $I$ specialise in production of good 1 and country $U$ specialises in production of good 2. Hence the wage rates in $C$ and $I$ are the values of marginal products of labour in producing good 1 in these two countries. Similarly wage rate in $U$ is given by the value of marginal product of labour in producing good 2 in $U$. The assumption of specialisation simplifies the analysis.

The wage rate of country $U$ is assumed to be greater than the wage rates of $C$ and $I$ which initiates migration. Migrants repatriate all the income to the home country. The national income of the home is the production of $X_{1}$ plus remittances received. Preferences are such that the countries always consume both goods, export the goods in which they specialise, and import the others. This pattern of comparative advantage is assumed not to be altered by migration ${ }^{1}$. The prices are assumed to be fixed throughout.

\footnotetext{
${ }^{1}$ We note that as migration effects the production and consumption of goods, it may also effect the world price levels and may reverse the pattern of the specialisation and wage differentials. As the aim
} 
To facilitate further analysis, assume for $i \in\{C, I\}$, that the production of $X_{1}$ is given as $X_{i 1}=a_{1} L_{i 1}-\frac{b_{1}}{2} L_{i 1}^{2}$, where $X_{i 1}$ denotes the amount of $X_{1}$ produced in $i$, $L_{i 1}$ is total amount of labour used in production of $X_{1}, a_{1}$ and $b_{1}$ are positive coefficients. Differentiating with respect to $L_{i 1}$, the value of the marginal product of labour in $X_{1}$ is obtained as $a_{1}-b_{1} L_{i 1}$.

The production of $X_{2}$ in $i \in\{C, I\}$ is given by $X_{i 2}=a_{2} L_{i 2}$, where $a_{2}$ is the amount of labour required to produce one unit of $X_{2}$ and $L_{i 2}$ is the amount of labour required for $X_{2}$. Differentiating with respect to $L_{i 2}$, the value of marginal product of labour is obtained as $a_{2}$. Country $i$ specialises in $X_{1}$ if the value of marginal product of labour in $X_{1}$ is greater than the value of marginal product of labour in $X_{2}$. That is, iff $a_{1}-b_{1} L_{i 1}>a_{2}$. Assume this holds, thus $i$ throughout specialises in production of $X_{1}$. Without migration the wage rate of $i$ is $w_{i}=a_{1}-b_{1} \bar{L}_{i}$.

On the other hand, assume that country $U$ has a linear production technology in producing $X_{1}$, given by $X_{u 1}=a_{u 1} L_{u 1}$ where $L_{u 1}$ is the amount of labour used and $a_{u 1}$ is the coefficient. The value of the marginal product of labour is $a_{u 1}$. The production function of $X_{2}$ is $X_{u 2}=a_{u 2} L_{u 2}-\frac{b_{u 2}}{2} L_{u 2}^{2}$, where $L_{u 2}$ is the amount of labour used in production of $X_{2}$ in $U$. The value of the marginal product of labour in

of the analysis is not to evaluate the welfare from trade and/or modification of comparative advantage, we assume fixed prices throughout to keep the analysis simple. The assumption of fixed prices also allows working with national income equation instead of a welfare function, as when prices are fixed, higher income implies higher welfare. Note that the world may consist of many goods, factors and countries whereas the paper works with only three countries, two goods and one factor. Our analysis, therefore, is partial and restrictive. The incorporation of more countries, goods and factors may change the results substantially. These assumptions and the functional forms selected are identical to Chowdhury (2014). 
$X_{2}$ is $a_{u 2}-b_{u 2} L_{u 2}$. Country $U$ specialises in production of $X_{2}$ iff $a_{u 2}-b_{u 2} L_{u 2}>a_{u 1}$. Assume this assumption holds and therefore $U$ specialises in production of $X_{2}$ throughout. Without migration, the workers of country $U$ receive wage $\bar{w}_{u}=a_{u 2}-b_{u 2} \bar{L}_{u}$.

With migration, the wage rate in $U$ is $w_{u}=a_{u 2}-b_{u 2}\left(\bar{L}_{u}+L_{C 2}+L_{I 2}\right)$. As assumed $w_{u}>a_{u 1}$, hence $U$ still specialises in production of good $X_{2}$ after migration. Also assume that $a_{u 2}-b_{u 2} \bar{L}_{u}>a_{1}-b_{1} \bar{L}_{i}$ as such, without migration, the wage received by labour in country $U$ is higher than that of $C$ and $I$, which initiates migration.

The timing is as follows. First the importing country, that is, country $U$ sets its tax policies for migration. Given the tax rates, $C$ and $I$ send labour to $U$ to receive remittances and maximise national income. It is possible for $C$ and $I$ to send all the labour to $U$ if wage gaps are large enough. To avoid such an extreme situation, we assume that migration equilibrium is reached well in advance of that.

\subsection{Defining the Mechanism of Migration}

This section defines the mechanism through which migration takes place. We assume that the governments of sending countries determine the outflow of migrants. This assumption may seem unreal at first look but is capable of capturing the migration of labour, from the Asian and Latin American countries to the rich and developed countries. 
The potential migrants of a developing country face mainly two barriers of migration. First, the labour markets are not integrated and secondly accessibility of job market information. For example, assume that a construction firm in the Middle East needs 1000 manual workers and it wants to recruit workers from countries like India, Bangladesh, Nepal, Pakistan or the Philippines. How the firm will recruit the workers? In most of the times, it is not possible to recruit these workers directly by publishing advertisement in the newspapers and internet. To overcome this problem, firms recruit workers from these countries through recruiting agencies operating at grass roots levels.

This recruitment process is now disfavoured by most countries. The employment contracts are often very abusive, the recruiters/agents often take high document processing fees, give false documents and do not ensure return migration (Oommen 2015, Wickramasekara 2016). The benefit of migration is often misappropriated by the middlemen. Hence governments are stepping in to control the labour recruitment process. Through inter-governmental negotiations, governments now establish the rules to govern migration related issues. The bilateral migration agreements observed worldwide depict direct involvement and interest of governments in this matter. In many countries, migration can now take place only through direct involvement of respective governments. In Canada's Seasonal Agricultural Workers Program, Canada mentions yearly demand to respective government authorities of Mexico and Caribbean countries. In reply Mexican and Caribbean governments facilitate recruitment according to the Canadian requirement (Verma, 2003). South Korea is now recruiting labour through 'Employment Permit System (EPS)' where workers are recruited only through the respective government bodies (see, www.eps.go.kr.index.html). 
In the paper, we overlook the possibility of imposition of a quota or a yearly demand that predetermine the number of migrants and instead assuming the sending countries can send as many as they like. This assumption however allows us to evaluate the policy responses of the receiving country in a simple and tractable way in line with the objective of the paper ${ }^{2}$.

Another argument could be that even if the governments of sending countries have direct interest, it is the individual migrants who decide whether they want to migrate or not. The model ensures that the net income of the migrants is higher than the wage rates at the countries of origin. We clarify it in the section 2.3.

\subsection{National Income Equations and Solutions of Migration}

We assume the following national income equations of the sending countries,

$Y_{i}=\left(a_{1}\left(\bar{L}_{i}-L_{i 2}\right)-\frac{b_{1}}{2}\left(\bar{L}_{i}-L_{i 2}\right)^{2}\right)+\left(a_{u 2}-b_{u 2}\left(\bar{L}_{u}+L_{i 2}+L_{j 2}\right)-T_{i}\right) L_{i 2}$

where,

$i \in\{C, I\}$ and $i \neq j$.

$Y_{i}=$ National income of $i$.

$L_{i 2}=$ Migrants from country $i$.

$L_{j 2}=$ Migrants from country $j$.

$T_{i}=$ Tax imposed by country $U$ on the migrants of country $i$.

\footnotetext{
${ }^{2}$ It will be interesting to have a model of bargaining involving negotiations of different stakeholders. In future attempts will be made to extend the analysis further in this direction.
} 
The above equation has two parts. The first part is the output produced within the country. The second part is the remittances sent by the workers working in $U$. The remittances are nothing but after tax income multiplied by total migrants. It is also assumed that migrants send the entire wage back to the home country. In reality migrants do keep some income in the country of immigration, buy properties or make investments. We are however assuming full repatriation of income to keep the analysis simple. Full repatriation of income also captures temporariness.

It is also assumed that the receiving country imposes taxes on the income of migrants. These taxes are proxies of immigration related monetary and non- monetary costs imposed by the country of immigration which are above the administrative costs of allowing immigration. This tax reflects the fact that in many parts of the world, migrants must pay taxes but may not receive equal benefit in return. These are particularly applicable to the temporary migrants. They often cannot to access various social, health and educational support programmes of the governments until have become legally permanent, but remain subject to payment of all type of taxes, as the permanent residents, for the whole period of stay.

The receiving country collects tax to be redistributed to the natives. When forming the strategies, the sending countries take the tax rates into consideration. The objective of the sending country $i$ is to maximise the national income with respect to $L_{i 2}$. The country assumes that the other country keeps the number of migrant labours the same. Differentiating with respect to $L_{i 2}$ and setting the derivatives equal to zero following two reaction functions for country $C$ and $I$ are obtained,

$$
\left(b_{1}+2 b_{u 2}\right) L_{C 2}=-\left(a_{1}-b_{1} \bar{L}_{C}\right)+\left(a_{u 2}-b_{u 2} \bar{L}_{u}\right)-T_{C}-b_{u 2} L_{I 2}
$$




$$
\left(b_{1}+2 b_{u 2}\right) L_{I 2}=-\left(a_{1}-b_{1} \bar{L}_{I}\right)+\left(a_{u 2}-b_{u 2} \bar{L}_{u}\right)-T_{I}-b_{u 2} L_{C 2}
$$

The reaction functions can be written in a manner to show that the wage received by migrants minus taxes are higher than the wages that can be obtained at home, which ensures that workers have incentive to migrate. Foreign wage minus taxes actually show the incomes of the migrants. It must be higher than the wages or marginal products at the home that is the marginal costs of the labour export.

The two equations can be solved for $L_{C 2}$ and $L_{I 2}$. The second derivatives satisfy the required conditions for maximisation. The solutions obtained are,

$$
L_{C 2}=Z^{-1}\left(B_{C}\left(b_{1}+2 b_{u 2}\right)-B_{I} b_{u 2}\right)
$$

and,

$$
L_{I 2}=Z^{-1}\left(B_{I}\left(b_{1}+2 b_{u 2}\right)-B_{C} b_{u 2}\right)
$$

where,

$$
\begin{aligned}
& Z=b_{1}\left(b_{1}+4 b_{u 2}\right)+3\left(b_{u 2}\right)^{2} \\
& B_{i}=-\left(a_{1}-b_{1} \bar{L}_{i}\right)+\left(a_{u 2}-b_{u 2} \bar{L}_{u}\right)-T_{i}
\end{aligned}
$$

$Z^{-1}$ is the inverse of $Z$. From the two solutions it is not possible to identify which country exports more labour. It depends on the amount of initial labour endowments and the tax rates. In later sections we will see how tax rates are imposed by country $U$. 


\section{Comparative Statics}

This section analyses how changes in the tax policy of $U$ effects the income and labour export of $i$. We describe the comparative statics results first and then illustrate how they have been derived.

Proposition 1: If tax rate $\left(T_{i}\right)$ of a country increases then the labour export from that country decreases but the labour export from the other country increases. The total labour export decreases.

Proof:

Assume that only tax rate for country $i$ has been changed. Differentiating the reaction functions of equations (2) and (3) with respect to $T_{i}$ we get,

$$
\begin{aligned}
& \left(b_{1}+2 b_{u 2}\right) \frac{\partial L_{i 2}}{\partial T_{i}}+b_{u 2} \frac{\partial L_{j 2}}{\partial T_{i}}=-1 \\
& b_{u 2} \frac{\partial L_{i 2}}{\partial T_{i}}+\left(b_{1}+2 b_{u 2}\right) \frac{\partial L_{j 2}}{\partial T_{i}}=0
\end{aligned}
$$

From the equations, the solutions obtained are,

$$
\frac{\partial L_{i 2}}{\partial T_{i}}=-Z^{-1}\left(b_{1}+2 b_{u 2}\right)<0
$$

and,

$$
\frac{\partial L_{j 2}}{\partial T_{i}}=Z^{-1} b_{u 2}>0
$$


Therefore, if the tax rate of a country is increased by $U$ then labour export from that country decreases but labour export from the other country increases. Adding the two we obtain,

$$
\frac{\partial L_{i 2}}{\partial T_{i}}+\frac{\partial L_{j 2}}{\partial T_{i}}=-Z^{-1}\left(b_{1}+b_{u 2}\right)<0
$$

Thus the overall labour export decreases.

The proposition (1) can be expressed using the following Figure.

\section{Insert Fig.1 here}

In Fig.1 the country I's reaction function is given by line (1) and country $C$ 's reaction function is given by line (2). The equilibrium of labour supply is given by $A$ where the two reaction functions intersect. Assume that the tax rate for country $C$ has been increased by $U$. As can be observed from equation (2), this reduces the intercept and shifts $C$ 's reaction function leftward. The new reaction function is denoted by (3). At the new equilibrium $B$, the labour export from $I$ increases and the labour export from $C$ decreases, but together the labour export decreases. The proposition comes directly from the requirement of the stability of the system. For stability it is required that the labour export should be in absolute value more 
responsive to the changes in own tax rate than the changes in the other country's tax rate.

Proposition 2: If $U$ increases the tax rate of a country, the national income of that country decreases and that of the other country increases.

\section{Proof:}

Differentiating the income equation of $i$ with respect to $T_{i}$ and using the first order condition ${ }^{3}$ in equations (2) or (3) we obtain,

$$
\frac{\partial Y_{i}}{\partial T_{i}}=-b_{u 2} L_{i 2} \frac{\partial L_{j 2}}{\partial T_{i}}-L_{i 2}<0
$$

Similarly differentiating the income equation of $j$ with respect to $T_{j}$ and using the first order condition,

$$
\frac{\partial Y_{j}}{\partial T_{i}}=-b_{u 2} L_{j 2} \frac{\partial L_{i 2}}{\partial T_{i}}>0
$$

Consequently, the national income of $i$ decreases and the national income of $j$ increases as $T_{i}$ increases.

${ }^{3}-\left(a_{1}-b_{1}\left(\bar{L}_{i}-L_{i 2}\right)\right)+\left(a_{u 2}-b_{u 2}\left(\bar{L}_{u}+2 L_{i 2}+L_{j 2}\right)-T_{i}\right)=0$ 
The proposition shows how the tax policy followed by the country $U$ effects the national income of the two labour exporting countries. A marginal increase in tax rate of $i$ reduces remittances, thereby the national income of $i$ falls. The country $i$ reduces the labour export. Therefore labour export and remittances received by $j$ increases.

We may also want to see what happens to the national output of $U$ with the increase in the tax rate. The national output equation of $U$ is,

$$
Y_{U}=a_{u 2}\left(\bar{L}_{u}+L_{i 2}+L_{j 2}\right)-\frac{b_{u 2}}{2}\left(\bar{L}_{u}+L_{i 2}+L_{j 2}\right)^{2}
$$

By differentiating with respect to $T_{i}$ we obtain,

$$
\frac{\partial Y_{U}}{\partial T_{i}}=\left(a_{u 2}-b_{u 2}\left(\bar{L}_{u}+L_{i 2}+L_{j 2}\right)\right)\left(\frac{\partial L_{i 2}}{\partial T_{i}}+\frac{\partial L_{j 2}}{\partial T_{i}}\right)
$$

The right side of the above equation is negative as obtained from proposition (1). Therefore the total output of $U$ falls i.e. $\frac{\partial Y_{U}}{\partial T_{i}}<0$.

\section{Determination of Tax Rates by the Importing Country}

The paper has until now analysed the effects of tax policies on the labour migration and the national incomes of the sending countries. In this section we turn our attention to the receiving country. It brings us to the first stage of the game, where 
$U$ sets the tax policies foreseeing the labour exports of $C$ and $I$. The tax policy, in addition, also depends on the national objectives of the receiving country. We have seen that the imposition of tax reduces the national output of $U$. The tax therefore must have other purposes. Sometimes the presence of a strong lobby is regarded as the reason for the use of a high import barrier. The same applies to the labour import. For example, a strong trade union or a lobby of workers may disfavour immigration. A lobby of capitalists may favour immigration. Some policies may increase the income of the whole nation whereas some policies may increase the income of a particular group. In the following proposition we look at such a motive of the imposition of tax.

Proposition 3: The receiving country may not always impose a positive tax rate to maximise the income of the permanent residents.

\section{Proof:}

To depict what is meant by the proposition, we first define the income equation of the permanent residents. The income of the permanent residents is given by the total national output minus the remittances that is,

$$
Y_{U N}=\left(a_{u 2}\left(\bar{L}_{u}+\sum_{i=I, C} L_{i 2}\right)-\frac{b_{u 2}}{2}\left(\bar{L}_{u}+\sum_{i=I, C} L_{i 2}\right)^{2}\right)-\left(a_{u 2}-b_{u 2}\left(\bar{L}_{u}+\sum_{i=I, C} L_{i 2}\right)\right) \sum_{i=I, C} L_{i 2}+\left(T_{i} L_{i 2}+T_{j} L_{j 2}\right)
$$


To prove the proposition, let us assume that only the tax rate for country $i$ has been changed. Differentiating equation (7) with respect to $T_{i}$ and assuming that tax the rates are initially zero we obtain,

$$
\frac{\partial Y_{U N}}{\partial T_{i}}=b_{u 2}\left(L_{i 2}+L_{j 2}\right)\left(\frac{\partial L_{i 2}}{\partial T_{i}}+\frac{\partial L_{j 2}}{\partial T_{i}}\right)+L_{i 2}
$$

Thus the first part of the equation is negative but as $L_{i 2}$ is positive the expression in total can have negative or positive sign. Thus when tax rates are zero, imposition of positive tax rates do not necessarily increase the income of the residents of $U$.

Further calculations with equation (8) do not clearly depict what is happening. The result however depends on the size of the relative labour import. To see it let us assume $b_{1}=b_{u 2}=1$, hence $\frac{\partial Y_{U N}}{\partial T_{i}}=-\frac{1}{4}\left(L_{i 2}+L_{j 2}\right)+L_{i 2}$. Therefore if $L_{j 2}>3 L_{i 2}$ then the imposition of a positive tax on $i$ hurts $U$.

The result is not unexpected but interestingly it depends largely on the responsiveness of the two countries to the changed tax rates. The income of the residents here is calculated by deducting the wages of migrants and adding the tax revenues to the national output. We saw before that the national output falls if the tax rate increases. Additionally as migration decreases, the wage of workers increases. Hence the output minus the wage of migrants falls. The country experiences an increase in the per capita tax revenue. If the increase in tax revenue can compensate for the loss of output minus remittances, the national income increases. It is 
interesting to note that the negativity or positivity of the expression depends on the relative magnitude of $\frac{\partial L_{i 2}}{\partial T_{i}}$ and $\frac{\partial L_{j 2}}{\partial T_{i}}$. We already know that the summation of these two terms is negative. The imposition of tax rate reduces the income of $U$ if the gap between them is sufficiently larger, that is if labour supply from $i$ decreases but the labour supply from $j$ does not increase by that extent. But if the gap between the two is close to zero then a positive tax may be proved beneficial for $U$. The proposition implies that $U$ may also use subsidies to improve the national income of the permanent residents.

The above proposition shows that the receiving country may not always follow the policy of a positive tax rate. However we have not yet seen how the competition of the countries effects the tax policy. To analyse this we work with a relatively simple case where $U$ aims to maximise the income of the permanent workers ${ }^{4}$. It is obvious that in this case $U$ uses a positive tax rate. This is nonetheless important as often the welfare of the native workers is given the highest weight in designing the immigration policy. A common perception is that the permanent workers income that is wage rate is the highest when there is no migration and for mainly this reason immigration receives objection from the native population. But it is often not reasonable for a country to completely prohibit migration. To cover for the loss of native workers, a country may offer some extra facilities and a part of these may come from the migrants, especially temporary workers. It is possible if the tax policy is designed in a way where migrant workers pay more tax relative to the benefits received.

The income equation of the permanent labour is,

\footnotetext{
${ }^{4}$ It implies that labour is not the only factor of production. The capital can be a hidden factor. How this tax policy effects the capitalists is an interesting topic but this paper does not explore it further.
} 


$$
Y_{L U}=\left(a_{u 2}-b_{u 2}\left(\bar{L}_{u}+L_{i 2}+L_{j 2}\right)\right) \bar{L}_{u}+T_{i} L_{i 2}+T_{j} L_{j 2}
$$

where $Y_{L U}$ is the income of the permanent workers. As shown in the above equation, $U$ now maximises the sum of the wages of the permanent workers and tax revenues. By evaluating the derivative when $T_{i}$ is zero we obtain,

$$
\frac{\partial Y_{L U}}{\partial T_{i}}=-b_{u 2} \bar{L}_{u}\left(\frac{\partial L_{i 2}}{\partial T_{i}}+\frac{\partial L_{j 2}}{\partial T_{i}}\right)>0
$$

Thus the imposition of tax increases the income of workers when tax rates are zero. The result differs from that of equation (7) where we looked at the whole national income.

With the assumption that the aim of government is to maximise the income of permanent workers, it is relatively easy to calculate the optimal tax rates for the exporting countries. The calculation is given in the appendix. The optimal solution is

$$
T_{i}=\frac{1}{2}\left(a_{u 2}-\left(a_{1}-b_{1} \bar{L}_{i}\right)\right)
$$

where $i=\{C, I\} . T_{i}$ is positive as by assumption $a_{u 2}>a_{1}-b_{1} \bar{L}_{i}^{5}$. From the equation it can be seen that the country with more labour endowment pays more tax, the

\footnotetext{
${ }^{5}$ It is possible that tax rate is so high that the labour export is zero. To ensure interior solution we assume that the parameters of the model are such that,

$\left(a_{u 2}-b_{u 2} \bar{L}_{u}\right)\left(b_{1}+b_{u 2}\right)-\frac{1}{2}\left(a_{1}-b_{1} \bar{L}_{i}\right)\left(b_{1}+2 b_{u 2}\right)-\frac{1}{2} a_{u 2}\left(b_{1}+2 b_{u 2}\right)+\frac{1}{2}\left(a_{1}-b_{1} \bar{L}_{j}\right) b_{u 2}+\frac{1}{2} a_{u 2} b_{u 2}>0$
} 
country endowed with less labour pays less tax. The above solution and the solutions for labour exports can be expressed by the following proposition:

Proposition 4: The country with the highest labour endowment pays the highest tax rate and supplies more labour. The labour supply of a country increases (decreases) if labour endowment of that country increases (decreases) and decreases (increases) if labour endowment of the other country increases (decreases).

\section{Proof:}

Equation (10) shows that the country with the highest labour endowment pays the highest tax rate. By substituting $T_{i}$ and $T_{j}$ in equations (4) and (5) and after necessary calculation (shown in appendix) we obtain,

$$
L_{i 2}-L_{j 2}=\frac{1}{2 Z} b_{1}\left(\bar{L}_{i}-\bar{L}_{j}\right)\left(b_{1}+3 b_{u 2}\right)
$$

If $\bar{L}_{i}>\bar{L}_{j}$ then the sign of the equation (11) is positive. That is $\bar{L}_{i}>\bar{L}_{j}$ implies that $i$ pays more tax and exports more labour.

The solution of the labour export is given in the appendix (equation A1). From that it can be seen that the labour export of a country increases with a decrease of the other country's labour endowment and decreases with the increase of the other country's labour endowment. The labour export increases with the increase of own labour endowment and decreases with the decrease of own labour endowment.

An intuitive explanation of the proposition (4) can be provided as follows. The workers of a labour endowed country receive lower wages in their home country. 
Thus the difference between wages received in $U$ and in the own country is highest for the country with the highest labour endowment. Therefore, $U$ extracts a higher rent by imposing a higher tax rate. As the labour supply is not perfectly inelastic, the importing country $U$ can exercise power when buying labour. Here the relation between the labour supply and the tax rate is downward sloping, which is similar to the revenue function of a monopolist. With a downward sloping demand a monopolist charges a higher price to the buyer with a lower elasticity of demand. A similar result has also been obtained in our analysis,

Proposition 5: The country with the highest labour endowment has the lowest tax elasticity of labour supply. If labour endowment of a country increases (decreases) then the labour supply of the other country becomes more elastic (inelastic).

\section{Proof:}

The elasticity is defined as $\eta_{T i i}=\frac{\partial L_{i 2}}{\partial T_{i}} / \frac{L_{i 2}}{T_{i}}$ where $\eta_{T i i}$ is the own tax elasticity of labour supply of the country $i$. As $\frac{\partial L_{i 2}}{\partial T_{i}}$ is same for both countries, the elasticity depends on how the ratio $\frac{L_{i 2}}{T_{i}}$ changes with the changes of labour endowments. In the appendix we obtain,

$$
\frac{L_{i 2}}{T_{i}}=\frac{Z^{-1}\left(-b_{u 2} \bar{L}_{u}\left(b_{1}+b_{u 2}\right)-\frac{1}{2}\left(a_{u 2}-\left(a_{1}-b_{1} \bar{L}_{j}\right)\right) b_{u 2}\right)}{\frac{1}{2}\left(a_{u 2}-\left(a_{1}-b_{1} \bar{L}_{i}\right)\right)}+Z^{-1}\left(b_{1}+2 b_{u 2}\right)
$$


The first terms of the expressions are negative, but in total the expressions must be positive because of the positivity of tax rates and labour supplies. By deducting (shown in the appendix) we obtain $\frac{L_{i 2}}{T_{i}}>\frac{L_{j 2}}{T_{j}}$ when $\bar{L}_{i}>\bar{L}_{j}$. Thus, the country with the highest labour endowment has the lowest tax elasticity of labour supply.

From equation (12), we observe that if $\bar{L}_{j}$ increases (decreases) then $\frac{L_{i 2}}{T_{i}}$ decreases (increases) and the labour supply become more elastic (inelastic).

The proposition has important policy implications. It is known that a monopolist varies price until the demand becomes inelastic. Here we observe that when the labour endowment of a country increases, the labour supply of the other country becomes more elastic. It delivers a greater power to the importing country in extracting rent.

Here we may point to the similarity of our paper with Brander and Spencer's analysis (Brander and Spencer, 1985). Brander and Spencer proposed a similar model where two countries export goods to a third country and analysed the optimum export tax/subsidy strategies of the exporting countries. Some papers have extended Brander and Spencer's analysis to include the importing country's policy response, i.e. Gatsios (1990) and Hwang and Mai (1991). In general it has been found that if the importing country practises discriminatory tariff policy, then the tariff rate is the highest for the most cost efficient exporter. Similarly, in our paper, the most cost efficient sending country (opportunity cost of migration is low) sends more migrants and pays the highest per capita tax. This result is also analogous to that obtained in Chowdhury (2014). 
As the analysis of the paper is mainly theoretical, the empirical validity of the findings needs to be established through further analysis. We observe that migrants do pay taxes in many forms but such taxes are apparently the same for all type of migrants. To find out the evidences of discriminatory tax rates, one needs to look at monetary and non monetary conditions attached to entry and access to social services. The results indicate that the sending countries' labour markets and bargaining positions effect the imposition of the tax rates. An empirical analysis relating the policies of the receiving countries with the labour market conditions of the sending countries will be useful in delivering further insight on this matter.

\section{Conclusions}

This paper analysed a model where two countries compete with each other to export labour to a third country. The concept of competition and cooperation is still a new idea in international migration. International bodies are encouraging and facilitating dialogues between countries in international migration issues. These dialogues may in the near future pave the way for a global consensus on migration.

In order to understand how international migration works it is important to consider the interests of different stakeholders of migration. Our paper could be useful to shed some light on this issue. In the paper, two countries aimed to maximise national incomes by sending workers to a third country. We observed that the importing country used discriminatory tax rates and the country with the highest labour endowment encountered the highest per capita tax rate. Though the result was theoretical, it indicated that the receiving countries may, in reality, practise 
discriminatory policies. One way the sending counties can retaliate is through collusion, that is, by jointly controlling the labour export. We have not analysed collusion in this paper but the exporting countries' collusion is by far an unobserved matter in international migration. Instead, we observe joint management and control of migration by the receiving countries. The Kafala system in the Gulf and the point based migration system followed by some developed countries are as examples of joint migration management by the importing countries.

The analysis of this paper has important policy implications. As international migration is important for many developing economies, the result of the paper suggested for the need of a collaborative effort of the Southern labour exporting countries in international migration issues. There is also a significant need for empirical works directed towards a detailed understanding of the subject matter i.e. the effects of competition for international migration on the policies of the receiving countries. Though our paper has not directly addressed, it is also linked to the question of the effectiveness of a foreign remittances dependent economic development policy that recently has been raised by other researchers (Hugo 2012, Wickramasekara 2016).

International migration is important for both developed and developing countries. In developed countries it helps to meet the shortage of manpower. In developing countries, it can increase national income and reduce the poverty level. However, the developing countries often do not realise how their unilateral labour export policies limit the potential benefit of migration and lead to higher exploitation. International migration is a multilateral issue involving both labour exporting and importing countries. Such a realisation is required for future initiatives linking migration and economic development. 


\section{References}

Brander, J. and Spencer, B (1985). Export subsidies and international market share rivalry. Journal of International Economics, Vol. 18, Issue 1-2, pp. 83-100.

Chau, N. and Kanbur, R. (2006). The race to the bottom, from the bottom. Economica, Vol. 73, Issue 290, pp. 193-228.

Chowdhury, M. (2014). Labour market integration, remittances and optimal tax policy. Migration and Development, Vol. 3, Issue 1, pp. 20-37.

Chowdhury, M. and Mukherjee A. (2015). Labour market integration and innovation: the implications on consumers. The Manchester School, Published online Nov. 12, 2015 (Early view, issue not assigned), DOI: 10.1111/manc.12132.

Comi, S. and Grasseni, M. (2011). Are temporary workers discriminated against? evidence from Europe. The Manchester School, Vol. 80, Issue 1, pp. 28-50.

Djajić, S. (2013). Some essentials of workable guest-workers program. International Economic Review, Vol. 54, Issue 2, pp. 739-766.

Djajić, S, Michael, S. and Vinogradova, A. (2012). Migration of skilled workers: policy interaction between host and source countries, Journal of Public Economics, Vol. 96, Issue 11-12, pp. 1015-1024

Docquier, F. and Rapoport, H. (2012). Globalization, brain drain and development. Journal of Economic Literature, Vol. 50, No. 3, pp. 681-730.

Gatsois, K. (1990). Preferential tariff and the 'Most Favoured Nation' principle: A note. Journal of International Economics, Vol. 28, Issue 3-4, pp. 365-33.

Hugo, G. (2012). Migration and development in low-income countries: a role for destination country policy?. Migration and Development, Vol. 1, Issue 1, pp. 2429. 
Hwang, H. and Mai, C. (1991). Optimum discriminatory tariffs under oligopolistic competition. Canadian Journal of Economics, Vol. 24, No. 3, pp. 693-702.

International Organization for Migration (2003). Labour migration in Asia: trends, challenges and policy responses in countries of origin. International Organization for Migration, Geneva.

Longva, A. (1999). Keeping migrant workers in check: the Kafala system in the Gulf. Middle East Report, Vol. 29, pp. 20-22.

Migrants Right (2008). India pushes for worker rights in Gulf. The Migrants Right, April 1, 2008. available on http://www.migrant-rights.org/2008/04/01/indiapushes-for-worker-rights-in-gulf/, Date accessed June 9, 2008.

Oommen, G. (2015). South Asia-Gulf Migratory corridor: emerging patterns, prospects and challenges. Migration and Development. Published online Mar. 18, 2015 (Issue not assigned). DOI:10.1080/21632324.2015.1010705

Schiff, M. (2007). Optimal immigration policy: permanent, guest-worker or mode IV?. IZA Discussion Papers 3083, IZA, Germany.

Shah, N. (2012). Socio-demographic transitions among nationals of GCC countries: implications for migration and labour force trends, Migration and Development. Vol. 1, Issue 1, pp. 128-138.

Verma, V. (2003). The Mexican and Caribbean seasonal agricultural workers program: regulatory and policy framework, farm industry level employment practices and the future of the program under unionization, Research Report, The North South Institute, Ottawa, Ontario, Canada. Available at: http://s3.amazonaws.com/migrants_heroku_production/datas/95/Verma_2003_ori ginal.pdf?1311163747, last accessed June, 25, 2014. 
Wickramasekara, P. (2016). South Asian migration to the Gulf: a safety valve or a development strategy. Migration and Development, Vol. 5, Issue 1, pp. 99-129. 


\section{Appendix}

\section{Optimal Tax rates}

To find the optimal rates of taxes, we differentiate equation (9) with respect to $T_{C}$ and $T_{I}$ and set the derivatives equal to zero,

$$
\frac{\partial Y_{L U}}{\partial T_{C}}=-b_{u 2} \bar{L}_{u}\left(\frac{\partial L_{C 2}}{\partial T_{C}}+\frac{\partial L_{I 2}}{\partial T_{C}}\right)+L_{C 2}+T_{C} \frac{\partial L_{C 2}}{\partial T_{C}}+T_{I} \frac{\partial L_{I 2}}{\partial T_{C}}=0
$$

and

$$
\frac{\partial Y_{L U}}{\partial T_{I}}=-b_{u 2} \bar{L}_{u}\left(\frac{\partial L_{C 2}}{\partial T_{I}}+\frac{\partial L_{I 2}}{\partial T_{I}}\right)+L_{I 2}+T_{C} \frac{\partial L_{C 2}}{\partial T_{I}}+T_{I} \frac{\partial L_{I 2}}{\partial T_{I}}=0
$$

The second derivatives from equation (9) are

$$
\frac{\partial Y_{L U}{ }^{2}}{\partial^{2} T_{i}}=-2 Z^{-1}\left(b_{1}+2 b_{u 2}\right)<0
$$

And,

$$
\frac{\partial Y_{L U}^{2}}{\partial T_{i} \partial T_{j}}=2 Z^{-1} b_{u 2}>0
$$

where $Z=b_{1}\left(b_{1}+4 b_{u 2}\right)+3\left(b_{u 2}\right)^{2}$

Setting the derivatives equal to zero and after necessary calculations we obtain, 
$-T_{C} 2\left(b_{1}+2 b_{u 2}\right)+T_{I} 2 b_{u 2}=-a_{u 2}\left(b_{1}+b_{u 2}\right)+\left(a_{1}-b_{1} \bar{L}_{C}\right)\left(b_{1}+2 b_{u 2}\right)-\left(a_{1}-b_{1} \bar{L}_{I}\right) b_{u 2}$

and

$2 T_{C} b_{u 2}-T_{I} 2\left(b_{1}+2 b_{u 2}\right)=-a_{u 2}\left(b_{1}+b_{u 2}\right)+\left(a_{1}-b_{1} \bar{L}_{I}\right)\left(b_{1}+2 b_{u 2}\right)-\left(a_{1}-b_{1} \bar{L}_{C}\right) b_{u 2}$

Solving using Cramer's rule

$4 Z T_{C}=$

$2 a_{u 2}\left(b_{1}+b_{u 2}\right)\left(b_{1}+2 b_{u 2}\right)-2\left(a_{1}-b_{1} \bar{L}_{C}\right)\left(b_{1}+2 b_{u 2}\right)^{2}+2\left(a_{1}-b_{1} \bar{L}_{I}\right)\left(b_{1}+2 b_{u 2}\right) b_{u 2}$

$+2 a_{u 2}\left(b_{1}+b_{u 2}\right) b_{u 2}-2\left(a_{1}-b_{1} \bar{L}_{I}\right)\left(b_{1}+2 b_{u 2}\right) b_{u 2}+2\left(a_{1}-b_{1} \bar{L}_{C}\right)\left(b_{u 2}\right)^{2}$

$=2\left(a_{u 2}-\left(a_{1}-b_{1} \bar{L}_{C}\right)\right)\left(\left(b_{1}\right)^{2}+4 b_{1} b_{u 2}+3\left(b_{u 2}\right)^{2}\right)$

As $Z=\left(b_{1}\right)^{2}+4 b_{1} b_{u 2}+3\left(b_{u 2}\right)^{2}$

$T_{C}=\frac{1}{2}\left(a_{u 2}-\left(a_{1}-b_{1} \bar{L}_{C}\right)\right)$

Similarly $T_{I}=\frac{1}{2}\left(a_{u 2}-\left(a_{1}-b_{1} \bar{L}_{I}\right)\right)$

Now substituting the solutions in equation (4), 


$$
\begin{aligned}
& L_{C 2}=Z^{-1}\left(\begin{array}{l}
\left(-\left(a_{1}-b_{1} \bar{L}_{C}\right)+\left(a_{u 2}-b_{u 2} \bar{L}_{u}\right)\right)\left(b_{1}+2 b_{u 2}\right)-T_{C}\left(b_{1}+2 b_{u 2}\right) \\
-\left(-\left(a_{1}-b_{1} \bar{L}_{I}\right)+\left(a_{u 2}-b_{u 2} \bar{L}_{u}\right)\right) b_{u 2}+T_{I} b_{u 2}
\end{array}\right) \\
& =Z^{-1}\left(\begin{array}{l}
\left(a_{u 2}-b_{u 2} \bar{L}_{u}\right)\left(b_{1}+b_{u 2}\right)-\left(\left(a_{1}-b_{1} \bar{L}_{C}\right)+\frac{1}{2}\left(a_{u 2}-\left(a_{1}-b_{1} \bar{L}_{C}\right)\right)\right)\left(b_{1}+2 b_{u 2}\right) \\
+\left(\left(a_{1}-b_{1} \bar{L}_{I}\right)+\frac{1}{2}\left(a_{u 2}-\left(a_{1}-b_{1} \bar{L}_{I}\right)\right)\right) b_{u 2}
\end{array}\right) \\
& =Z^{-1}\left(\begin{array}{l}
\left(a_{u 2}-b_{u 2} \bar{L}_{u}\right)\left(b_{1}+b_{u 2}\right)-\frac{1}{2}\left(a_{1}-b_{1} \bar{L}_{C}\right)\left(b_{1}+2 b_{u 2}\right)-\frac{1}{2} a_{u 2}\left(b_{1}+2 b_{u 2}\right) \\
+\frac{1}{2}\left(a_{1}-b_{1} \bar{L}_{I}\right) b_{u 2}+\frac{1}{2} a_{u 2} b_{u 2}
\end{array}\right)
\end{aligned}
$$

Similarly $L_{I 2}$ is obtained from equation (5). Deducting them we get,

$$
L_{C 2}-L_{I 2}=\frac{1}{2 Z} b_{1}\left(\bar{L}_{C}-\bar{L}_{I}\right)\left(b_{1}+3 b_{u 2}\right)
$$

We assume that the value of the parameters of the model are such that $L_{i 2}>0$

\section{Calculation of elasticity}

We will only show the calculation of $\frac{L_{C 2}}{T_{C}}$ in detail, 


$$
\begin{aligned}
& \left.\frac{L_{C 2}}{T_{C}}=\frac{\left(\begin{array}{l}
\left.\left(a_{u 2}-b_{u 2} \bar{L}_{u}\right)\left(b_{1}+b_{u 2}\right)-\frac{1}{2}\left(a_{1}-b_{1} \bar{L}_{C}\right)\left(b_{1}+2 b_{u 2}\right)-\frac{1}{2} a_{u 2}\left(b_{1}+2 b_{u 2}\right)\right) \\
+\frac{1}{2}\left(a_{1}-b_{1} \bar{L}_{I}\right) b_{u 2}+\frac{1}{2} a_{u 2} b_{u 2}
\end{array}\right)}{\frac{1}{2}\left(a_{u 2}-\left(a_{1}-b_{1} \bar{L}_{C}\right)\right)}\right) \\
& =\frac{Z^{-1}\left(\begin{array}{l}
\left.\left(a_{u 2}-b_{u 2} \bar{L}_{u}\right)\left(b_{1}+b_{u 2}\right)+\frac{1}{2}\left(a_{u 2}-\left(a_{1}-b_{1} \bar{L}_{C}\right)\right)\left(b_{1}+2 b_{u 2}\right)\right) \\
-\frac{1}{2}\left(a_{u 2}-\left(a_{1}-b_{1} \bar{L}_{I}\right)\right) b_{u 2}-a_{u 2}\left(b_{1}+b_{u 2}\right)
\end{array}\right)}{\frac{1}{2}\left(a_{u 2}-\left(a_{1}-b_{1} \bar{L}_{C}\right)\right)}+Z^{-1}\left(b_{1}+2 b_{u 2}\right) \\
& =\frac{Z^{-1}\left(\left(a_{u 2}-b_{u 2} \bar{L}_{u}\right)\left(b_{1}+b_{u 2}\right)-\frac{1}{2}\left(a_{u 2}-\left(a_{1}-b_{1} \bar{L}_{I}\right)\right) b_{u 2}-a_{u 2}\left(b_{1}+b_{u 2}\right)\right)}{\frac{1}{2}\left(a_{u 2}-\left(a_{1}-b_{1} \bar{L}_{C}\right)\right)}+Z^{-1}\left(b_{1}+2 b_{u 2}\right) \\
& Z^{-1}\left(-b_{u 2} \bar{L}_{u}\left(b_{1}+b_{u 2}\right)-\frac{1}{2}\left(a_{u 2}-\left(a_{1}-b_{1} \bar{L}_{I}\right)\right) b_{u 2}\right) \\
& \left.=\frac{1}{2}\left(a_{1}-b_{1} \bar{L}_{C}\right)\right)
\end{aligned}
$$

Calculating the ratio for the other country and by deducting we get,

$$
\begin{aligned}
& \frac{L_{C 2}}{T_{C}}-\frac{L_{I 2}}{T_{I}}=-\frac{Z^{-1}\left(b_{u 2} \bar{L}_{u}\left(b_{1}+b_{u 2}\right)\right)}{\frac{1}{2}\left(a_{u 2}-\left(a_{1}-b_{1} \bar{L}_{C}\right)\right)}+\frac{Z^{-1}\left(b_{u 2} \bar{L}_{u}\left(b_{1}+b_{u 2}\right)\right)}{\frac{1}{2}\left(a_{u 2}-\left(a_{1}-b_{1} \bar{L}_{I}\right)\right)} \\
& -\frac{Z^{-1}\left(\frac{1}{2}\left(a_{u 2}-\left(a_{1}-b_{1} \bar{L}_{I}\right) b_{u 2}\right)\right)}{\frac{1}{2}\left(a_{u 2}-\left(a_{1}-b_{1} \bar{L}_{C}\right)\right)}+\frac{Z^{-1}\left(\frac{1}{2}\left(a_{u 2}-\left(a_{1}-b_{1} \bar{L}_{C}\right) b_{u 2}\right)\right)}{\frac{1}{2}\left(a_{u 2}-\left(a_{1}-b_{1} \bar{L}_{I}\right)\right)}
\end{aligned}
$$

As $\bar{L}_{C}>\bar{L}_{I}$ or $T_{C}>T_{I}$, the expression has a positive sign. 


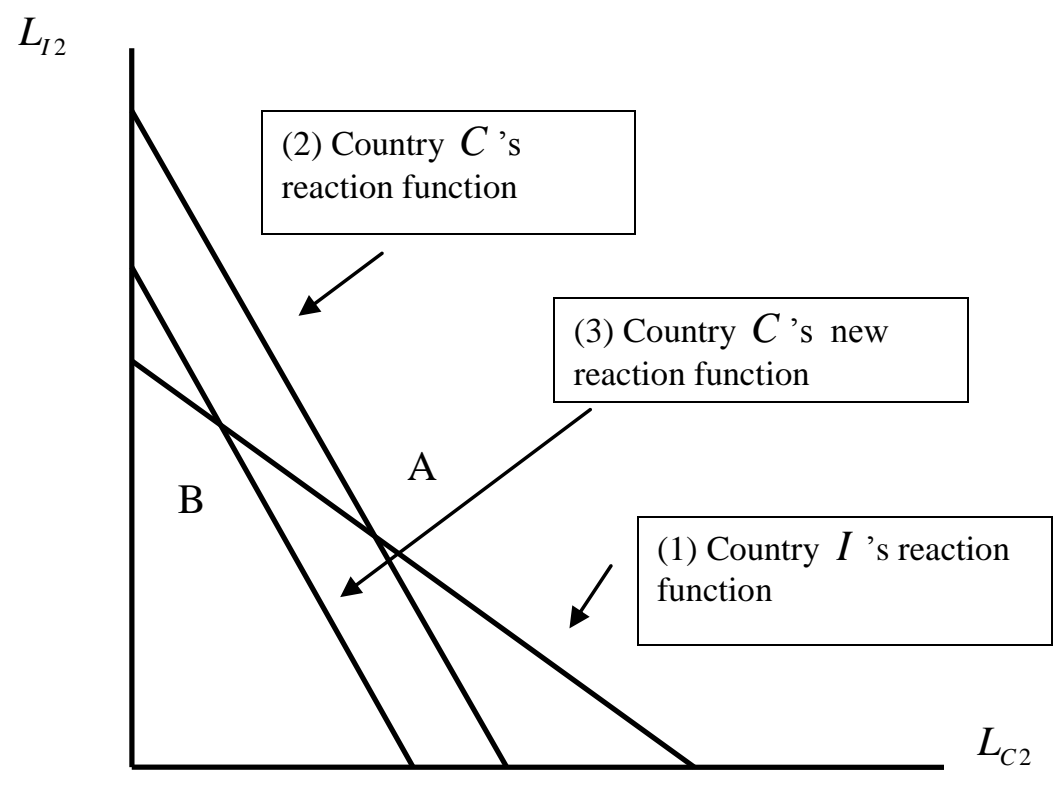

Fig.1. Equilibrium Labour Export 